\title{
The Insurance Value of Trade Credit
}

\author{
Mario Eboli $^{1} \&$ Andrea Toto ${ }^{1}$ \\ ${ }^{1}$ Dipartimento di Economia Aziendale, Università 'G. d'Annunzio', Pescara, Italy \\ Correspondence: Mario Eboli, Dipartimento di Economia Aziendale, Università 'G. d'Annunzio', viale Pindaro \\ 42, 65127 Pescara, Italy. Tel: 39-347-482-4246. E-mail: m.eboli@unich.it
}

Received: March 29, 2019

Accepted: April 18, 2019

Online Published: June 14, 2019

doi:10.5539/ijef.v11n7p

URL: https://doi.org/10.5539/ijef.v11n7p87

\begin{abstract}
The extensive use of trade credit in all manufacturing sectors, despite its high cost, is an apparent puzzle that economists explain in terms of asymmetric information problems affecting financial markets. The financial constraints arising from credit rationing and limited access to stock markets suffice to induce firms to resort to trade credit as a supplemental source of funding. Nonetheless, empirical evidence shows that also large and liquid firms facing no binding financial constraints use substantial amounts of trade credit. We address this issue by modelling the financial policy of a firm that does not face a binding liquidity constraint but the risk of being constrained in the future. We characterise the optimal amount of trade credit held by such a firm, and we show that a positive probability of facing a liquidity constraint leads the firm to fund its inventories with trade credit, even if cheaper sources of funds are available. The rationale is that trade credit provides implicit coverage against liquidity risk. Therefore, the optimal amount of trade credit grows with the expected size of a possible liquidity shock and with the likelihood of its occurrence.
\end{abstract}

Keywords: trade credit, liquidity risk, insurance, corporate finance

\section{Introduction and Motivation}

In the last two decades, trade credit has attracted the attention of economists because it posed a puzzle. Empirical evidence shows an abundant and widespread use of trade credit. Several studies-e.g. Atanasova and Wilson (2003), Cuñat (2007), Rajan and Zingales (1994), Guedes and Mateus (2009)-present data showing that trade credit is a substantial share of the liabilities of firms in all manufacturing sectors. Likewise, significant amounts of account receivables appear among the assets of most companies. This extensive use of trade credit appears surprising in the light of its high cost. Indeed, the cost of trade credit, i.e. its implicit interest rate, is significantly higher than the cost of a bank loan (Note 1). If trade credit is so expensive, why do companies resort to it so extensively? Why such a large share of credit is not provided by banks and financial intermediaries, which are specialized in credit services? Why do suppliers regularly grant trade credit to their clients?

Understandably, economists put forward explanations of this phenomenon based on informational imperfections in credit and financial markets. As is known, asymmetric information between lenders and borrowers create problems of adverse selection and moral hazard resulting in credit rationing and costly-if not impossible-access to stock markets. Firms facing these financial constraints can resort to trade credit as a supplementary source of funding.

Indeed, several authors argue that credit rationing and financial constraints explain the broad use of trade credit. Petersen and Rajan $(1994,1997)$ find that firms that are less likely to face bank credit constraints tend to rely less on trade credit, whereas firms with weak relationships with banks rely more on trade credit. They also find that companies with large cash flows are more inclined to provide more trade credit to their buyers. Nilsen (1994, 2002) presents empirical results showing that firms react to monetary contractions by resorting to trade credit. When the interest rates increase, because of tighter monetary policy, small firms avoid credit rationing by using more trade credit. Similarly, Gertler and Gilchrist (1993a, 1993b) suggest that small firms that are likely to suffer bank credit rationing borrow more from their suppliers during monetary contractions. According to Biais and Gollier (1997), economies in which the relationships between banks and firms are robust and financial markets are more efficient, such as the US, show a less intense use of trade credit. On the contrary, economies with less developed financial markets and more distant bank-firm relationships, such as France, tend to show a wider use of trade credit. 
Although the arguments presented by the above-cited authors appear convincing, they leave unanswered part of the observed phenomenon. If liquidity constraints are the cause of the wide use of trade credit as a source of funding, why large, liquid firms with access to credit and stock markets also show significant amounts of trade credit among their liabilities? Why liquidity constraint firms grant trade credit to their customers?

To expound this empirical evidence, authors like Wilner (2000) and Cuñat (2007) also invoke credit market imperfections and focus on some implicit and explicit features of trade credit contracts. These authors argue that providers of trade credit grant more concessions to their buyers than other financial intermediaries. In order to keep enduring business relationships with their buyers, the suppliers of a firm are willing to extend further credit if the firm experiences financial difficulties, whereas banks would not do so. Cuñat (2007) develops and reinforces the same argument. This author demonstrates that the suppliers of inputs of production have a comparative advantage, with respect to financial intermediaries, in providing liquidity insurance to their clients. This is explained by the fact that suppliers are better informed than banks about a firm's creditworthiness, have more contract enforcement power than banks (because of the industrial relation with the buyer) and, finally, can make better use of the trade credit collaterals, i.e. the inventories of the firm. Consequently, "Suppliers seem to lend to their customers experiencing financial trouble, even when banks are not willing to lend. This additional lending may occur through financing a higher proportion of purchased goods or by extending the agreed maturity of the loans. Furthermore, in many circumstances, this extra lending occurs via late payment of already extended debts." (Cuñat, 2007).

The theoretical arguments of these authors find ample support from empirical evidence. Boissay and Gropp (2013) present an extensive dataset on French firms showing that liquidity constrained firms that experience liquidity shocks pass part of such shocks to their suppliers by deferring their payments, i.e. increasing their trade credit obligations. These data indicate that, in the vast majority of cases, suppliers do not pursue the liquidation of their illiquid buyers and accept to postpone payments, which means to augment the trade credit granted to the buyer.

These empirical and theoretical findings indicate that, generally, suppliers act as lenders of last resort for firms that face financial troubles. This marks a substantial difference between bank and trade credit. A firm cannot default on a bank without incurring in a liquidation procedure, i.e. bankruptcy. Conversely, a firm can default on its suppliers and count on a deferral of payments, i.e. extra funding. Therefore, while granting trade credit, suppliers also act as providers of insurance against liquidity risk.

The aim of this paper is to contribute to this stream of literature presenting a result that isolates the insurance value of trade credit from its value as a supplemental source of funding. We focus on a buyer's side of this story and model the behaviour of a risk-neutral, value-maximising firm that does not face a binding liquidity constraint but the risk of being constrained in the future. We characterise the optimal amount of trade credit held by such a firm. In so doing, we show that a positive probability of facing a liquidity constraint is sufficient to induce the firm to fund its inventories with trade credit, even if cheaper sources of funds are available. Moreover, we obtain that, as intuition suggests, the optimal amount of trade credit grows with the size of the expected liquidity shock and with the likelihood of its occurrence.

The rest of the paper is organised as follows. Section 2 presents a review of the literature on trade credit that is related to the present paper. Section 3 puts forward a model of the optimal choice of funds of a manufacturing firm and the results that we obtain about the funding of production with trade credit. Conclusions are drawn in Section 4 while the proofs of the proposition and corollary presented in Section 3 are collected in the Appendix.

\section{Related Literature}

Our work is related to the studies that focus on the role of trade credit in manufacturing sectors and put forward possible explanations for its extensive use.

As mentioned in the introduction, authors such as Petersen and Rajan (1994, 1997), Gertler and Gilchrist (1993a, 1993b), Nilsen (1994, 2002) and Biais and Gollier (1997) argue that the liquidity constraints due to bank credit rationing explain the widespread resort to trade credit, despite its high cost. These authors see trade credit as a source of funding supplementary and complementary to bank credit. As Biais and Gollier (1997) argue, suppliers are better informed than banks about the creditworthiness of a firm. This informational advantage renders possible the realisation of profitable projects through trade credit, projects that banks would not have funded. Another compelling argument in Biais, Gollier (1997) is that the granting of trade credit by suppliers is a favourable signal for the banks. The information revealed by a trade credit contract helps to alleviate the problems of asymmetric information resulting in credit rationing. In this perspective, bank credit and trade credit are complementary: the larger the amount of trade credit granted to a firm, the more solvent the firm appears to 
the banks.

$\mathrm{Ng}$ et al. (1999) too analyse trade credit contracts from the perspective of asymmetric information and signalling. Suppliers face imperfect information about buyers' default risk, and they address this problem offering trade credit with specific contractual terms. Buyers' responses to such contractual terms are signals about their financial soundness and, therefore, they help the suppliers to identify the buyers who may face liquidity shortages. The empirical results of this paper support the theories that describe credit terms as contractual solutions to moral hazard problems concerning product quality and buyer creditworthiness. Similar arguments appear in Smith (1987), who claims that the trade credit contract provides an effective screening device of default risk, and this explains its high implicit interest rate. The author models a two-part trade credit agreement as a screening contract, according to which if a buyer forgoes the discount then he pays a rather high-interest rate. In these cases, the failure to take the discount is a negative signal that confirms the need to monitor the buyer's financial position.

Carpenter, Fazzari, Petersen (1998) explain the observed cycles of investment in inventories in terms of financial constraints. They argue that cash flows and trade credit are much more statistically significant than cash stocks in explaining the investment in inventories, i.e. in working capital. They test this hypothesis across different manufacturing sectors and for firms of different sizes. Their results support the view of a linkage between inventories and trade credit, where the latter is a source of funding of the former.

Contributions that are more recent deliver further investigations of the nature and implications of trade credit contracts. Cunat (2007) analyses the relationship between supplier and customer from an industrial and financial point of view. The author argues that suppliers have a comparative advantage over banks in granting loans because trade credit contacts are more enforceable than bank credit contracts. Suppliers can threaten to stop supplying inputs of production, and this constitutes a more effective means of enforcement than the mere legal means available to the banks. Cunat (2007) also presents data showing that, in Great Britain, trade credit amounts to $17 \%$ of total assets, $43 \%$ of debts and $52 \%$ of short-term debts of companies, whereas in the US these percentages are $18 \%, 34 \%$ and $58 \%$, respectively.

Asymmetric information and moral hazard problems are at the heart of the analyses by Burkart and Ellingsen (2004). These authors present a contract theoretic model of trade credit in competitive markets with asymmetric information and argue that trade credit reduces the scope for moral hazard on the part of debtors. For this reason, according to the authors, the weaker the legal protection of creditors provided by the judicial system, the larger the use of trade credit. They also argue that trade credit and bank credit are complementary for firms subject to liquidity constraints, while they are substitutes for firms with sufficient debt capacity, i.e. firms that have access to external sources of funding tend not to resort to trade credit.

Wilner (2000) argues that the providers of trade credit, differently from financial intermediaries, are willing to grant more concessions to buyers in financial distress because of their interest in maintaining an enduring business relationship. The high-interest rate required by the suppliers constitutes a fair premium for buyers that would receive extra funding in case of financial difficulties. The author argues that a buyer can take advantage of this facet of a trade credit contract in case the buyer's purchases represent a large percentage of the supplier's revenues. In this case, the buyer accepts what appears to be a less favourable contract because it implies more negotiating power in the presence of financial shortages.

Aktasa et al. (2012) highlight the information content of trade credit contracts. These authors argue that the use of trade credit reveals valuable information to outside investors in as much as it improves the quality of the investments of a firm. The authors test and validate this prediction using balance-sheet data taken from a large sample of US firms, using several proxies for firm's investment quality.

In a more recent contribution, Abdulla et al. (2017) point out the different use of trade credit made by publicly listed firms and privately held firms. These authors show that public firms have a significantly lower level of trade credit than private firms do. They explain the finding arguing that public firms have access to sources of finance cheaper than trade credit, while private firms are more likely to face bank credit constraints.

Finally, it is worth citing Yang and Birge (2014), who study the effects of the extensive use of trade credit in supply chains. They find that there is a high statistical correlation between account payables and inventory stocks. According to the authors, this indicates that trade credit helps to improve the efficiency of supply chains.

\section{The Model}

We model the behaviour of a risk-neutral, value-maximiser firm, i.e. a firm that maximises the discounted sum of future expected profits, and focus on the financial needs arising from its activity (Note 2). The firm operates with 
three inputs: fixed capital, $K_{t}$, labour, $L_{t}$, and working capital, i.e. inventories, $I_{t}$. The latter is the stock of intermediate goods used in the production process. For simplicity, we take the amount of labour as fixed, i.e. as provided by a set of workers who have a long-term contract with the firm. We assume that the firm is endowed with a Cobb-Douglas technology and it is subject to the possible occurrence of random productivity shocks:

$$
Y_{t}=\theta_{t} K_{t}^{\alpha} I_{t}^{\beta} L_{t}^{\gamma}
$$

Where i) $+\beta+\gamma=1$, and ii) $\theta_{t}$ is a random variable that can take on two values: either unity, with probability $1-p$, or $\hat{\theta}<1$, with probability $p$. The productivity shock occurs if $\theta_{t}=\hat{\theta}$. If, conversely, $\theta_{t}=1$, then the firm faces no adverse condition and implements the desired, optimal amount of output, $Y_{t}^{*}$, using the optimal amount of factors, i.e. $K_{t}^{*}, I_{t}^{*}$ and $L_{t}^{*}$. The price of the output is assumed constant and is normalised to one. Hence, $Y_{t}$ measures also the revenues of the firm. For the sake of simplicity, we take the amount of labour, $L$, as fixed and equal to its desired value, i.e. we assume that the firm has a set of workers, hired with long-term contracts, who deliver the optimal, profit-maximising amount of labour. Thus, the firm pursues its desired level of production choosing the investments in inventories and, possibly, in fixed capital. As customary, we assume that inventories stock is nondurable and fully depreciates after one period, whereas fixed capital, $K_{t}$, is durable and irreversible (Note 3), that is:

$$
\Delta K_{t} \geq 0
$$

The firm finances its activity using net earnings, an internal source of cash, and two external sources of funding: bank credit, $b$, and trade credit, $T C$. Banks behave competitively and are willing to lend and borrow at an interest rate equal to $r$. The suppliers of the firm provide trade credit by granting to their customers the possibility of deferring payments at a cost. We introduce financial markets imperfections in the model by assuming that the firm faces a bank credit constraint and cannot issue new shares. We assume that the banks, to grant credit to the firm, require a collateral guarantee and that a share $v$ of the capital endowment $K_{t}$ can serve this purpose. Moreover, we assume that the firm cannot obtain extra funding from its shareholders, i.e. from the stock market.

At the beginning of each period, the firm borrows one-period debt, $b_{t}$, from the banks at the interest rate $r$, and repays to the banks $b_{t} * R$ at the end of the period, where $R=1+r$. Formally, we assume that

$$
b_{t} \leq v K_{t}
$$

Where $0<v<1$, and

$$
\pi_{t} \geq 0
$$

where i) $v$ is the share of fixed capital that can serve as collateral, and ii) $\pi_{t}$ represents the profits of the firm that are distributed to the shareholders, i.e. dividends. The non-negativity of dividends means that shareholders cannot provide further funding to the firm. The firm can retain partly or entirely its profits--i.e. its net earnings, as defined below--and can lend them to the banks at a risk-free interest rate equal to $r$. Such a rate sets the opportunity cost of this source of funding. At the beginning of a period, the firm can also obtain one-period trade credit from its supplier of inventories. We assume that the firm can purchase the entire amount of inventories with trade credit, that is

$$
T C_{t} \leq I_{t}
$$

The cost of trade credit, i.e. its implicit interest rate, is $r_{1}>r$. At the end of the period, the firm is supposed to repay $T C_{t} \cdot R_{1}$ to the suppliers, where $R_{1}=1+r_{1}$. Moreover, and most important, we assume that the firm can choose not to repay part or all of the existing trade credit. Because of the theoretical and empirical results cited above, we assume that a supplier never asks for the liquidation of a defaulting buyer and always accepts to defer the repayment of trade credit to the next period, without imposing a penalty rate on such extended loans. In other words, we assume that the firm can choose to repay the portion $(1-D) T C_{t}$ of trade credit, where $D \in[0,1]$, within the initial contractual terms (i.e. at the end of the period), and defer the repayment of the portion $D \cdot T C_{t}$ to the subsequent period, paying the same interest rate, $r_{1}$.

To characterise the forward-looking optimal behaviour of the firm, we consider a succession of three periods, i.e. three production cycles, indicated as time $t, t+1$ and $t+2$. At the beginning of each period, the firm observes the realisation of $\theta_{t}$ and decides the level of activity, i.e. chooses the profit-maximising investment in inventories and fixed capital. Moreover, at the beginning of each period, the firm obtains credit $b_{t}$ from the bank and can obtain trade credit $T C_{t}$ from its supplier, if the firm chooses to do so. The firm uses these funds, along with the net earnings of the preceding period,

$$
Y_{t-1}-b_{t-1} \cdot R-T C_{t-1} \cdot R_{1},
$$

to finance the purchase of the production factors that yield the output $Y_{t}$. At the end of each period, the firm 
realises revenues $Y_{t}$, and it is supposed to repay the debt to the banks, $b_{t} \cdot R$, and the trade credit, if any, to its suppliers, $T C_{t} \cdot R_{1}$. If $T C_{t}>0$, the firm has the option to postpone the repayment of trade credit. Thus, at the beginning of each period, the firm faces the following cash flow statement that shows the sources and the uses of funds:

$$
\pi_{t}+I_{t}+\omega L_{t}+\Delta K_{t}=Y_{t-1}-b_{t-1} \cdot R+b_{t}-(1-D) T C_{t-1} \cdot R_{1}+T C_{t}
$$

The value-maximising behaviour of the firm at hand consists of choosing the values of the choice variables-- $b$, $T C, I, K$ and $D$-with the aim of maximising the present value, at time $t$, of its stream of profits over the three periods. Formally, the decision problem of the firm is

$$
\max _{t}=\max _{b, T C, I, K, D}\left\{\pi_{t}+\frac{1}{R} E_{t}\left[\pi_{t+1}\right]+\frac{1}{R^{2}} E_{t}\left[\pi_{t+2}\right]\right\}
$$

Subject to: $\Delta K_{t} \geq 0, b_{t} \leq v K_{t}, \pi_{t} \geq 0$ and $T C_{t} \leq I_{t}$

For the sake of simplicity, we restrict the possibility of a productivity shock to the first period only, i.e. we assume that $\theta_{t+1}=\theta_{t+2}=1$, whereas $\theta_{t}=\hat{\theta}$ with probability $p$ and $\theta_{t}=1$ with probability $1-p$.

Thus, the firm faces two possible scenarios. A first scenario, in which no productivity shock occurs in any of the three periods, and the firm faces no liquidity constraint. A second scenario, in which the shock takes place in the first period and the firm experiences a liquidity shortage. This restriction on the occurrence of the shock is not crucial. We could extend the possibility of the existence of the shock to the second and third period without changing the substance of our results but, in so doing, we would render the solution of the model more cumbersome. Conversely, the next two restrictions are fundamental for our analysis.

Assumption 1: The bank credit constraint, $b_{t} \leq v K_{t}$, is not binding, in the sense that, if no shock occurs, then the firm can fund its optimal level of activity without resorting to trade credit

$$
I_{t+1}^{*}+\omega L_{t+1}^{*}+\Delta K_{t+1}^{*} \leq Y_{t}-b_{t} \cdot R+b_{t+1}
$$

Since trade credit is more expensive than retained profits and bank credit, this assumption implies that, in the absence of productivity shocks, the firm pays inventories upfront.

Assumption 2: In the absence of trade credit, the shock is sufficiently large to force the firm to reduce the activity level in the subsequent period

$$
I_{t+1}^{*}+\omega L_{t+1}^{*}+\Delta K_{t+1}^{*}>Y_{t}(\hat{\theta})-b_{t} \cdot R+b_{t+1}
$$

This restriction means that net earnings and further bank credit--if it is available, i.e. if $b_{t}<v K_{t}-$ are not sufficient to cover the liquidity shortage generated by the productivity shock, if the shock is sufficiently large, i.e. if

$$
\hat{\theta}<\left[I_{t+1}^{*}+\omega L_{t+1}^{*}+\Delta K_{t+1}^{*}+b_{t} \cdot R-b_{t+1}\right] / Y_{t}(\hat{\theta}) .
$$

In this case, the amount of output realised by the firm in period $t+1$ is strictly smaller than its profit-maximising value, i.e. $Y_{t+1}<Y_{t+1}^{*}$.

With these assumptions, we restrict the analysis to the behaviour of a firm that does not deal with a binding liquidity constraint but faces a liquidity risk, i.e. the risk of being liquidity constraint in the future. Under these conditions, trade credit is not a convenient source of funding stricto sensu, because of its high cost, but can be a valid source of funding because of its implicit insurance function, despite its high cost. We now proceed to show that it is indeed so and characterise the optimal amount of trade credit that a profit-maximising firm holds under the restrictions made above.

\section{Proposition:}

Under the above-stated conditions, the optimal amount of trade credit held by the firm at hand is

$$
T C_{t}^{*}=\frac{E_{t} \frac{\partial Y_{t+1}}{\partial D}+\frac{\operatorname{cov}\left(\frac{\partial Y_{t+1}}{\partial D}, \phi_{t+2}\right)}{1+E_{t} \phi_{t+2}}}{R_{1}^{2}-R_{1} R}
$$

where $\partial Y_{t+1} / \partial D$ is the marginal productivity of retained trade credit at time $t+1$, and $\phi_{t+2}$ is the shadow price of retained profits at time $t+2$.

\section{Corollary:}

1) The optimal amount of trade credit held by the firm at hand, $T C_{t}^{*}$, is strictly positive:

$$
T C_{t}^{*}=\operatorname{argmax}_{T C}\left\{V_{t}\right\}>0
$$


2) $T C_{t}^{*}$ is strictly increasing in the probability of the occurrence of the shock, $p$, and in the size of the shock, i.e. it is strictly decreasing in $\hat{\theta}$.

These results establish that the insurance value of trade credit per se is sufficient to induce a liquid firm to hold trade credit. A firm that does not need trade credit as a supplemental source of funding, i.e. a firm that can fund its activity with cash flows and bank credit, uses trade credit as a form of insurance against liquidity risk. The extra cost of trade credit, i.e. the difference $R_{l}-R$, is the price that a firm pays to buy the option of defaulting on its suppliers, if necessary. The extent of this liquidity insurance is the maximum amount of extra funds that the firm can obtain from its suppliers, i.e. is the value of the inventories purchased with trade credit.

As shown by eq. (8), and claimed in the corollary, the optimal quantity of trade credit grows in the likelihood of the occurrence of the shock, $p$, i.e. in the risk of being financially constraint, and in the magnitude of the possible liquidity shortage, $(1-\hat{\theta}) Y_{t}^{*}$. Thus, the larger the exposure to liquidity risk, the larger $T C_{t}^{*}$. On the other hand, the more expensive this form of insurance, i.e. the larger $R_{I}-R$, the larger the denominator of eq. (8), the smaller $T C_{t}^{*}$, i.e. the insurance coverage purchased by the firm in this fashion.

\section{Conclusions}

The trade credit puzzle described above has prompted different analyses and different explanations. There is wide agreement on the fact that firms subject to credit rationing and limited access to stock markets resort to trade credit as a supplemental source of funding. Nonetheless, empirical evidence shows that the extensive use of trade credit in the manufacturing sector also involves large and liquid firms that have access to sources of funding cheaper than trade credit. We focused on this facet of the phenomenon and analysed the conduct of a risk-neutral, profit-maximising manufacturing firm that does not experience a binding financial constraint but only the risk of being constrained in the future. Based on theoretical arguments and empirical evidence put forward by several authors, we assume that suppliers of goods are willing to grant further credit to their customers if these face financial difficulties. That is, suppliers of goods are also providers of insurance against the risk of facing a liquidity shortage. We argue that this liquidity insurance embedded in trade credit contracts is sufficient to justify the use of trade credit on the part of a firm that has sufficient internal and external funding-i.e. cash flows and bank credit-to funds its optimal level of activity. We characterise the optimal quantity of trade credit held by such a firm under the assumption that the firm can default on its suppliers without facing a bankruptcy procedure. Our results show that the value-maximising amount of trade credit for this firm is a function of its exposure to liquidity risk. In other words, the optimal amount of trade credit is the optimal purchase of insurance against liquidity shocks undertaken by the firm at hand. Our results also show that, as intuition suggests, the optimal quantity of trade credit is an increasing function of the expected size of the possible liquidity shortages and their likelihood, whereas it is decreasing in the difference between the cost of trade credit and the cost of cheaper sources of funding, such as bank credit.

In sum, our analysis indicates that the rationale of the fact that large and liquid firm, i.e. firms that have sufficient cash flows and bank credit to buffer ordinary fluctuations of their net earnings, hold substantial quantities of trade credit if they operate under the risk of unfavourable events capable of resulting in large liquidity shortages.

\section{References}

Abdulla, Y., Anh, D. V., \& Khurshed, A. (2017). Stock market listing and the use of trade credit: Evidence from public and private firms. Journal of Corporate Finance, 46, 391-410. https://doi.org/10.1016/j.jcorpfin.2017.08.004

Aktasa, N., de Bodt, E., Lobez, F., \& Statnik, J. C. (2012). The information content of trade credit. Journal of Banking \& Finance, 36(5), 1402-1413. https://doi.org/10.1016/j.jbankfin.2011.12.001

Atanasova, C. V., \& Wilson, N. (2003). Bank borrowing constraints and the demand for trade credit: Evidence from panel data. Managerial and Decision Economics, 24(6-7), 503-514. https://doi.org/10.1002/mde.1134

Biais, B., \& Gollier, C. (1997). Trade credit and credit rationing. Review of Financial Studies, 10(4), 903-937. https://doi.org/10.1093/rfs/10.4.903

Boissay, F., \& Gropp, R. (2013). Payment Defaults and Interfirm Liquidity Provision. Review of Finance, 17(6), 1853-1894. https://doi.org/10.1093/rof/rfs045

Burkart, M., \& Ellingsen, T. (2004). In-Kind Finance: A Theory of Trade Credit. American Economic Review, 94(3), 569-590. https://doi.org/10.1257/0002828041464579

Caggese, A. (2007). Financing Constraints, Irreversibility, and Investment Dynamics. Journal of Monetary Economics, 54, 2102-2130. https://doi.org/10.1016/j.jmoneco.2006.10.001 
Cannari, L., Chiri S., \& Omiccioli, M. (2004). Condizioni di credito commerciale e differenziazione della clientele. Banca d'Italia, Temi di Discussione, n. 495.

Carpenter, R. E., Fazzari, S. M., \& Petersen, B. (1998). Financing constraints and inventory investment: A comparative study with high-frequency panel data. The Review of Economics and Statistics, 80, 513-519. https://doi.org/10.1162/003465398557799

Gertler, M., \& Gilchrist, S. (1993a). The role of credit market imperfections in the monetary transmission mechanism: arguments and evidence. The Scandinavian Journal of Economics, 95(1), 43-64. https://doi.org/10.2307/3440134

Gertler, M., \& Gilchrist, S. (1993b). The cyclical behaviour of short-term business lending: Implications for financial propagation mechanisms. European Economic Review, 37, 623-631. https://doi.org/10.1016/0014-2921(93)90052-C

Guedes, J., \& Mateus, C. (2009). Trade credit linkages along the supply chain: Evidence for the Italian textile sector. European Financial Management Association 2009 Annual Meetings, 24-27 Jun 2009, Milan, Italy.

Ng, C. K., Smith, J. K., \& Smith, R. L. (1999). Evidence on the Determinants of Credit Terms Used in Inter firm Trade. The Journal of Finance, 54(3), 1109-29. https://doi.org/10.1111/0022-1082.00138

Nilsen, J. (1994). The Impact of Credit Markets on Monetary Policy. Princeton University, PhD dissertation.

Petersen, M. A., \& Rajan, R. G. (1994). The Benefits of Lending Relationships: Evidence from Small Business Data. The Journal of Finance, 49, 3-37. https://doi.org/10.1111/j.1540-6261.1994.tb04418.x

Petersen, M. A., \& Rajan, R. G. (1997). Trade Credit: Theories and Evidence. Review of Financial Studies, 10(3), 661-691. https://doi.org/10.1093/rfs/10.3.661

Wilner, B. S. (2000). The Exploitation of Relationships in Financial Distress: The Case of Trade Credit. The Journal of Finance, 55, 153-178. https://doi.org/10.1111/0022-1082.00203

Yang, S. A., \& Birge, J. R. (2014). How Inventory Is (Should Be) Financed: Trade Credit in Supply Chains with Demand Uncertainty and Costs of Financial Distress. https://doi.org/10.2139/ssrn.1734682

\section{Notes}

Note 1. Empirical evidence shows that the implicit interest rate of trade credit contract is generally much higher than the interest rates on bank loans. See, inter alia, Ng et al. (1999) and Atanasova and Wilson (2003). See also Cannari et al. (2004), who study the terms and costs of trade credit in Italy.

Note 2. The present modeling approach, which focuses on the optimal investment in current activity of a firm and on its financial requirements, is common in the recent literature on the effects of financial constraints on the investment in working capital, e.g. Caggese (2007).

Note 3. For the sake of simplicity, and without loss of generality, we forego the depreciation of fixed capital.

\section{Appendix}

Proof of proposition: Since

$$
E_{t}\left[\pi_{t+1}\right]=p \pi_{t+1}\left(\theta_{t+1}=\hat{\theta}\right)+(1-p) \pi_{t+1}\left(\theta_{t+1}=1\right)
$$

and

$$
E_{t}\left[\pi_{t+2}\right]=p \pi_{t+2}\left(\theta_{t+1}=\hat{\theta}\right)+(1-p) \pi_{t+2}\left(\theta_{t+1}=1\right)
$$

rewrite eq. (7) as:

$$
V_{t}=\max _{b_{t}, T c_{t}, I_{t}, K_{t}, D}\left\{\begin{array}{l}
\pi_{t}+p \frac{1}{R} \pi_{t+1}\left(\theta_{t+1}=\hat{\theta}\right)+p \frac{1}{R^{2}} \pi_{t+2}\left(\theta_{t+1}=\hat{\theta}\right)+ \\
+(1-p) \frac{1}{R} \pi_{t+1}\left(\theta_{t+1}=1\right)+(1-p) \frac{1}{R^{2}} \pi_{t+2}\left(\theta_{t+1}=1\right)
\end{array}\right\}
$$

The optimal amount of trade credit chosen at time $t$ is

$$
T C_{t}^{*}=\operatorname{argmax}_{T C}\left\{V_{t}\right\}=\operatorname{argmax}_{T C}\left\{\begin{array}{l}
\pi_{t}+p \frac{1}{R} \pi_{t+1}\left(\theta_{t}=\hat{\theta}_{t}\right)+p \frac{1}{R^{2}} \pi_{t+2}\left(\theta_{t}=\hat{\theta}_{t}\right)+ \\
+(1-p) \frac{1}{R} \pi_{t+1}\left(\theta_{t}=1\right)+(1-p) \frac{1}{R^{2}} \pi_{t+2}\left(\theta_{t}=1\right)
\end{array}\right\}
$$


The amount of trade credit that maximises the fourth and fifth addenda of $V_{t}$ is equal to zero because, if $\theta_{t}=1$, then the firm is not financially constrained and it prefers to use sources of funds cheaper than trade credit, i.e. retained profits and bank debt. Thus, to characterise $T C_{t}^{*}$ we can look at the first order conditions of the constraint optimisation problem of the firm, i.e. eq. (7a), in the second of the above-described scenarios, i.e. the one in which $\left(\theta_{t+1}=\hat{\theta}\right)$. Formally, we have that

$$
T C_{t}^{*}=\operatorname{argmax}_{T C}\left\{V_{t}\right\}=\operatorname{argmax}_{T C}\left\{W_{t}\right\},
$$

where

$$
W_{t}=\max _{b_{t}, T C_{t}, I_{t}, K_{t}, D}\left\{\pi_{t}+p \frac{1}{R} \pi_{t+1}\left(\theta_{t+1}=\hat{\theta}\right)+p \frac{1}{R^{2}} \pi_{t+2}\left(\theta_{t+1}=\hat{\theta}\right)\right\}
$$

Subject to: $\Delta K_{t} \geq 0, b_{t} \leq v K_{t}, \pi_{t} \geq 0$ and $T C_{t} \leq I_{t}$

Let the Lagrange multipliers associated with these constraints be represented as follows: $\mu_{t}$ for the irreversibility of fixed capital, $\Delta K_{t} \geq 0 ; \lambda_{t}$ for the bank credit constraint, $b_{t} \leq v K_{t} ; \phi_{t}$ for the non-negativity of dividends, $\pi_{t} \geq 0$ and, finally, $\sigma_{t}$ for the trade credit constraint, $T C_{t} \leq I_{t}$.

The cash flow statement, eq. (6), for the three periods and for $\theta_{t+1}=\hat{\theta}$ are the following

$$
\begin{gathered}
\pi_{t}+I_{t}+\omega L_{t}+\Delta K_{t}=Y_{t-1}-b_{t-1} \cdot R+b_{t}-T C_{t-1} \cdot R_{1}+T C_{t} \\
\pi_{t+1}+I_{t+1}+\omega L_{t+1}+\Delta K_{t+1}=Y_{t}-b_{t} \cdot R+b_{t+1}-(1-D) T C_{t} \cdot R_{1}+T C_{t+1} \\
\pi_{t+2}+I_{t+2}+\omega L_{t+2}+\Delta K_{t+2}=Y_{t+1}-b_{t+1} \cdot R+b_{t+2}-D T C_{t} \cdot R_{1}^{2}-T C_{t+1} \cdot R_{1}+T C_{t+2}
\end{gathered}
$$

rearranging

$$
\begin{gathered}
\pi_{t}=Y_{t-1}-b_{t-1} \cdot R+b_{t}-T C_{t-1} \cdot R_{1}+T C_{t}-I_{t}-\omega L_{t}-\Delta K_{t} \\
\pi_{t+1}=Y_{t}-b_{t} \cdot R+b_{t+1}-(1-D) T C_{t} \cdot R_{1}+T C_{t+1}-I_{t+1}-\omega L_{t+1}-\Delta K_{t+1} \\
\pi_{t+2}=Y_{t+1}-b_{t+1} \cdot R+b_{t+2}-D T C_{t} \cdot R_{1}^{2}-T C_{t+1} \cdot R_{1}-I_{t+2}-\omega L_{t+2}-\Delta K_{t+2}
\end{gathered}
$$

Then the Lagrangean function that represents the maximand at hand is

$$
\begin{gathered}
\Lambda=\pi_{t}-\phi_{t}\left(-\pi_{t}\right)-\mu_{t}\left(-\Delta K_{t}\right)-\lambda_{t}\left(b_{t}-v K_{t}\right)-\sigma_{t}\left(T C_{t}-I_{t}\right)+ \\
\frac{1}{R} E_{t}\left\{\pi_{t+1}-\phi_{t+1}\left(-\pi_{t+1}\right)-\mu_{t+1}\left(-\Delta K_{t+1}\right)-\lambda_{t+1}\left(b_{t+1}-v K_{t+1}\right)-\sigma_{t+1}\left(T C_{t+1}-I_{t+1}\right)\right\}+ \\
\frac{1}{R^{2}} E_{t}\left\{\pi_{t+2}-\phi_{t+2}\left(-\pi_{t+2}\right)-\mu_{t+2}\left(-\Delta K_{t+2}\right)-\lambda_{t+2}\left(b_{t+2}-v K_{t+2}\right)-\sigma_{t+2}\left(T C_{t+2}-I_{t+2}\right)\right\}
\end{gathered}
$$

rearranging:

$$
\begin{gathered}
\Lambda=\pi_{t}+\phi_{t} \pi_{t}+\mu_{t} \Delta K_{t}-\lambda_{t}\left(b_{t}-v K_{t}\right)+\sigma_{t}\left(I_{t}-T C_{t}\right)+ \\
\frac{1}{R} E_{t}\left\{\pi_{t+1}+\phi_{t+1} \pi_{t+1}+\mu_{t+1} \Delta K_{t+1}-\lambda_{t+1}\left(b_{t+1}-v K_{t+1}\right)+\sigma_{t+1}\left(I_{t+1}-T C_{t+1}\right)\right\}+ \\
\frac{1}{R^{2}} E_{t}\left\{\pi_{t+2}+\phi_{t+2} \pi_{t+2}+\mu_{t+2} \Delta K_{t+2}-\lambda_{t+2}\left(b_{t+2}-v K_{t+2}\right)+\sigma_{t+2}\left(I_{t+2}-T C_{t+2}\right)\right\} \\
\pi_{t}=Y_{t-1}-b_{t-1} \cdot R+b_{t}-T C_{t-1} \cdot R_{1}+T C_{t}-I_{t}-\omega L_{t}-\Delta K_{t} \\
\pi_{t+1}=Y_{t}-b_{t} \cdot R+b_{t+1}-(1-D) T C_{t} \cdot R_{1}+T C_{t+1}-I_{t+1}-\omega L_{t+1}-\Delta K_{t+1} \\
\pi_{t+2}=Y_{t+1}-b_{t+1} \cdot R+b_{t+2}-D T C_{t} \cdot R_{1}^{2}-T C_{t+1} \cdot R_{1}-I_{t+2}-\omega L_{t+2}-\Delta K_{t+2}
\end{gathered}
$$

To characterise $T C_{t}^{*}$, we have look at the first order condition with respect to the choice variable $D$ :

$$
\frac{\partial \Lambda}{\partial D}=\frac{1}{R} E_{t}\left\{R_{1} T C_{t}\left(1+\phi_{t+1}\right)\right\}+\frac{1}{R^{2}} E_{t}\left\{-R_{1}^{2} T C_{t}\left(1+\phi_{t+2}\right)+\frac{\partial Y_{t+1}}{\partial D}+\frac{\partial Y_{t+1}}{\partial D} \phi_{t+2}\right\}=0
$$

hence

$$
\frac{\partial \Lambda}{\partial D}=\frac{R_{1}}{R} T C_{t}\left(1+E_{t} \phi_{t+1}\right)-\frac{R_{1}^{2}}{R^{2}} T C_{t}\left(1+E_{t} \phi_{t+2}\right)+\frac{1}{R^{2}} E_{t} \frac{\partial Y_{t+1}}{\partial D}+\frac{1}{R^{2}} E_{t} \frac{\partial Y_{t+1}}{\partial D} \phi_{t+2}=0
$$

Since $\operatorname{COV}(X, Y)=E[X Y]-E[X] \cdot E[Y]$, we set: 


$$
E_{t}\left[\frac{\partial Y_{t+1}}{\partial D} \phi_{t+2}\right]=\operatorname{COV}\left(\frac{\partial Y_{t+1}}{\partial D}, \phi_{t+2}\right)+E\left[\frac{\partial Y_{t+1}}{\partial D}\right] \cdot E\left[\phi_{t+2}\right]
$$

and the above equation becomes

$$
\begin{aligned}
\frac{\partial \Lambda}{\partial D}=\frac{R_{1}}{R} T C_{t}(1 & \left.+E_{t} \phi_{t+1}\right)-\frac{R_{1}^{2}}{R^{2}} T C_{t}\left(1+E_{t} \phi_{t+2}\right)+\frac{1}{R^{2}} E_{t} \frac{\partial Y_{t+1}}{\partial D}+\frac{1}{R^{2}} \operatorname{COV}\left(\frac{\partial Y_{t+1}}{\partial D}, \phi_{t+2}\right) \\
+ & \frac{1}{R^{2}} E\left[\frac{\partial Y_{t+1}}{\partial D}\right] \cdot E\left[\phi_{t+2}\right]=0
\end{aligned}
$$

Rearranging

$$
\frac{\partial \Lambda}{\partial D}=\frac{R_{1}}{R} T C_{t}\left(1+E_{t} \phi_{t+1}\right)-\frac{R_{1}^{2}}{R^{2}} T C_{t}\left(1+E_{t} \phi_{t+2}\right)+\frac{1}{R^{2}} E_{t}\left[\frac{\partial Y_{t+1}}{\partial D}\right]\left(1+E_{t} \phi_{t+2}\right)+\frac{1}{R^{2}} \operatorname{COV}\left(\frac{\partial Y_{t+1}}{\partial D}, \phi_{t+2}\right)=0
$$

Manipulating and simplifying, we obtain:

$$
\begin{aligned}
& \frac{1}{R^{2}} E_{t}\left[\frac{\partial Y_{t+1}}{\partial D}\right]=-\frac{R_{1}}{R} T C_{t} \frac{1+E_{t} \phi_{t+1}}{1+E_{t} \phi_{t+2}}+\frac{R_{1}^{2}}{R^{2}} T C_{t} \frac{1+E_{t} \phi_{t+2}}{1+E_{t} \phi_{t+2}}-\frac{1}{R^{2}} \frac{\operatorname{COV}\left(\frac{\partial Y_{t+1}}{\partial D}, \phi_{t+2}\right)}{1+E_{t} \phi_{t+2}} \\
& E_{t}\left[\frac{\partial Y_{t+1}}{\partial D}\right]=-R_{1} R T C_{t} \frac{1+E_{t} \phi_{t+1}}{1+E_{t} \phi_{t+2}}+R_{1}^{2} T C_{t}-\frac{\operatorname{COV}\left(\frac{\partial Y_{t+1}}{\partial D}, \phi_{t+2}\right)}{1+E_{t} \phi_{t+2}} \\
& E_{t}\left[\frac{\partial Y_{t+1}}{\partial D}\right]=T C_{t}\left[R_{1}^{2}-R_{1} R \frac{1+E_{t} \phi_{t+1}}{1+E_{t} \phi_{t+2}}\right]-\frac{\operatorname{COV}\left(\frac{\partial Y_{t+1}}{\partial D}, \phi_{t+2}\right)}{1+E_{t} \phi_{t+2}}
\end{aligned}
$$

and, finally, we obtain the profit-maximising amount of trade credit:

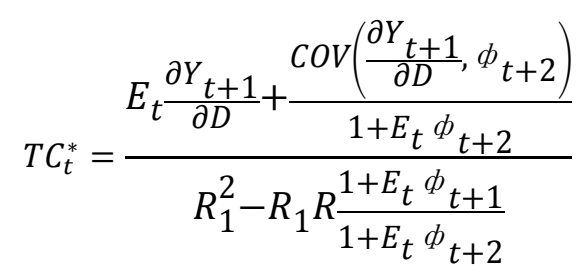

Note that the expected values of the Lagrange multiplier $\phi$ measured at time $t+1$ and at time $t+2$ are both equal to the cost of trade credit: $E_{t} \phi_{t+1}=E_{t} \phi_{t+2}=r_{1}$. The Lagrange multiplier $\phi$ measures the marginal value of extra cash coming from net earnings, i.e. retained profits. This value is the same at time $t+1$ and at time $t+2$ because in both periods the firm is financially constrained with a marginal cost of funding equal to the cost of trade credit, $r_{1}$. In other words, one extra dollar of retained profits enables the firm to save one dollar of retained trade credit. Hence, we have

Proof of corollary:

$$
T C_{t}^{*}=\frac{E_{t} \frac{\partial Y_{t+1}}{\partial D}+\frac{\operatorname{cov}\left(\frac{\partial Y_{t+1}}{\partial D}, \phi_{t+2}\right)}{1+E_{t} \phi_{t+2}}}{R_{1}^{2}-R_{1} R} \text {. Q.e.d. }
$$

Point 1: The denominator of this ratio is positive because of $R_{1}>R$. The numerator is positive because: i) $\partial Y_{t+1} / \partial D>0$, i.e. the marginal productivity of $D$ in period $t+1$ is positive. Retaining an additional unit of trade credit $T C_{t}$ at time $t+1$ enables the firm to increase its investments and reduce the gap between the actual and the optimal level of production. ii) $\operatorname{COV}\left(\partial Y_{t+1} / \partial D, \phi_{t+2}\right)>0 . \partial Y_{t+1} / \partial D$ and $\phi_{t+2}$ are both binary random variables that depend on the realisation of the shock. If $\left(\theta_{t}=1\right)$, then they are both nulls: the firm is not financially constraint, retained trade credit has no impact on investment decisions and the constraint $\pi_{t} \geq 0$ is not binding. If $\left(\theta_{t}=\hat{\theta}\right)$, then both these variables take on positive values because the firm faces a binding financial constraint. Indeed, in such a case, $\partial Y_{t+1} / \partial D>0$ and $\phi_{t+2}=r_{1}>0$. Therefore, $T C_{t}^{*}>0$.

Point 2: Under assumption 1, we have that the investment in inventories and fixed capital, made by the firm at the beginning of period $t$, are $I_{t}^{*}$ and $K_{t}^{*}$, i.e. the ones that, along with the optimal amount of labour, deliver the 
optimal, profit-maximising volume of output, $Y_{t}^{*}$. If $\left(\theta_{t}=\hat{\theta}\right)$, then the firm realises $\hat{\theta} Y_{t}^{*}$ and the resulting liquidity shortage, due to the unexpected reduction of the earnings cashed in at the end of the period, is $(1-\hat{\theta}) Y_{t}^{*}$. Since labour is fixed and the stock of fixed capital is optimal, the liquidity constraint limits the investment in inventories at time $t+1$. The larger $(1-\hat{\theta}) Y_{t}^{*}$, the larger the gap between the optimal and the actual purchase of inventories, unless the firm retains part or all of the trade credit obtained at the beginning of the period. Therefore, if $\left(\theta_{t}=\hat{\theta}\right)$, the smaller $\hat{\theta}$, the larger $(1-\hat{\theta}) Y_{t}^{*}$, the larger the marginal productivity of liquidity at time $t+1$, hence the larger the realised value of $\partial Y_{t+1} / \partial D$. Recall that the latter is one of the two possible realisations of the corresponding random variable, thus the larger $(1-\hat{\theta})$, the larger the variance of the random variable $\partial Y_{t+1} / \partial D$. Moreover, recall that $D T C_{t}^{*}$ is sufficient to purchase the optimal amount of inventories at time $t+1$. It follows that the expected value of one extra unit of internal funding, $E_{t} \Phi_{t+2}=r_{1}$ is invariant with respect the size of the shock (it remains equal to the cost of one extra unit of retained trade credit) and so is its variance. Thus, $\operatorname{cov}\left(\left(\partial Y_{-}(t+1)\right) / \partial D, E_{t} \Phi_{t+2}\right)$ decreases in $\hat{\theta}$, i.e. it increases in the size of the shock. Therefore, the numerator of $T C_{t}^{*}$ decreases in $\hat{\theta}$, i.e. $T C_{t}^{*}$ increases in the size of the shock, $(1-\hat{\theta}) Y_{t}^{*}$. Finally, the fact that $T C_{t}^{*}$ is increasing in $p$ is evident from equation (7b). End of proof.

\section{Copyrights}

Copyright for this article is retained by the author(s), with first publication rights granted to the journal.

This is an open-access article distributed under the terms and conditions of the Creative Commons Attribution license (http://creativecommons.org/licenses/by/4.0/). 